\title{
SSCP analysis of paraffin wax embedded tissues in a family with an atypical form of Fabry disease
}

\author{
Kirsten Marie Madsen, Lis Hasholt, Johannes Berger, Sven Asger Sørensen
}

\begin{abstract}
To investigate the distribution of a single base pair mutation within a family with one known case of Fabry disease, DNA from paraffin wax embedded necropsy material was studied using single-strand conformation polymorphism (SSCP) analysis. The proband, who presented with an atypical form of Fabry disease, had a $G$ to $A$ transition in exon 6 of the $\alpha$-galactosidase $A$ gene. This patient had mainly cardiac symptoms and late onset disease. Further cases of coronary disorders occurred in this family, including the proband's brother who died at 42 years of age of a cardiac disorder. Formalin fixed, paraffin wax embedded material from the brother and two more distant relatives was available for analysis. SSCP analysis showed that the proband's brother also carried the $G$ to $A$ transition. Thus, the atypical form of Fabry disease and unrelated cardiac diseases with similar clinical symptoms occurred within a single family. The variant form is rare but may account for a few of the numerous cases of cardiac disease in men and should be considered when clusters of cases of cardiac disease occur within a single family. (F Clin Pathol: Mol Pathol 1996;49:M310-M312)
\end{abstract}

Keywords: Fabry disease, $\alpha$-galactosidase, SSCP, paraffin embedded tissue, cardiac disease.

The clinical course of Fabry disease is usually characterised by acroparesthesia and angiokeratoma in childhood and by vascular disease of the brain, heart and kidneys in the second to fifth decades of life. However, several cases of atypical variants of Fabry disease with milder manifestations have been described. ${ }^{1}$ Among these the cardiac variants are characterised by cardiomyopathy and mild proteinuria.

Fabry disease is caused by deficiency of the lysosomal enzyme $\alpha$-galactosidase A ( $\alpha$-gal A). The gene encoding this enzyme resides on the $\mathrm{X}$ chromosome, covers 12 kilobases and is comprised of seven exons. ${ }^{2}$ In the past few years about 80 different mutations have been identified..$^{3-8}$ The mutations are dispersed throughout the gene and are usually specific to each affected family.

Among Danish patients with Fabry disease, one proband with very low $\alpha$-gal A activity had the cardiac form of the disease. ${ }^{9} \mathrm{He}$ was the only confirmed case of Fabry disease in this family and the question arose whether it was a de novo mutation or whether other relatives were also affected. The proband's brother and mother had both died of heart disease at the age of 42 and 62 years, respectively and other cardiac disorders were present in more distant relatives.

The aim of the present paper is to describe the utility of paraffin wax embedded tissues for the postmortem diagnosis of Fabry disease and to report a second case of the atypical form in this family.

\section{Methods}

PATIENTS

The proband, III:2 (arrow; fig 1), underwent a routine examination at the age of 52 years which showed proteinuria, albuminuria and haematuria. A kidney biopsy specimen was suggestive of Fabry disease as many foamy cells were observed. The very low $\alpha$-gal $A$ activity in lymphocytes $(34.2 \mu \mathrm{mol} / \mathrm{mg}$ protein/hour (normal range 202.2-594.3)) and cultured fibroblasts $(73.9 \mu \mathrm{mol} / \mathrm{mg}$ protein/hour (normal range 268.0-413.0)), measured as described by Desnick et $a l,{ }^{10}$ confirmed the diagnosis. The mutation was detected by single-strand conformation polymorphism (SSCP) analysis and sequencing showed a $G$ to $A$ transition in exon 6 at position 902 (R301Q) ${ }^{8}$ The proband felt entirely healthy until aged 57 years, when he developed arthralgia and cardiomyopathy with oedema and dyspnoea. He died at the age of 62 years from severe cardiac insufficiency and had no other symptoms of Fabry disease, such as angiokeratoma or acroparesthesia. ${ }^{9}$

The proband's brother, III: 3 , died at the age of 42 years of a cardiac arrest. He had been hospitalised several times since the age of 36 with typical symptoms of acute myocardial infarction. Renal function was stated as normal. Necropsy revealed pathological changes in the heart only: severe coronary arteriosclerosis and left ventricular hypertrophy with a recent infarct and fibrosis corresponding to earlier infarcts. Both parents had had an acute myocardial infarction. We have reviewed the hospital records but there was nothing indicative of Fabry disease in either the brother or the mother.

\section{SSCP ANALYSIS}

We succeeded in obtaining paraffin wax embedded tissues originating from probands III:3, II:3 and III:8; there was necropsy material from the testes, myocardia and cerebellum, respectively. DNA was extracted by adding $1 \mathrm{ml}$ xylene to 10 sections of formalin fixed, paraffin wax embedded tissue. Sections were then incubated for 30 minutes at 


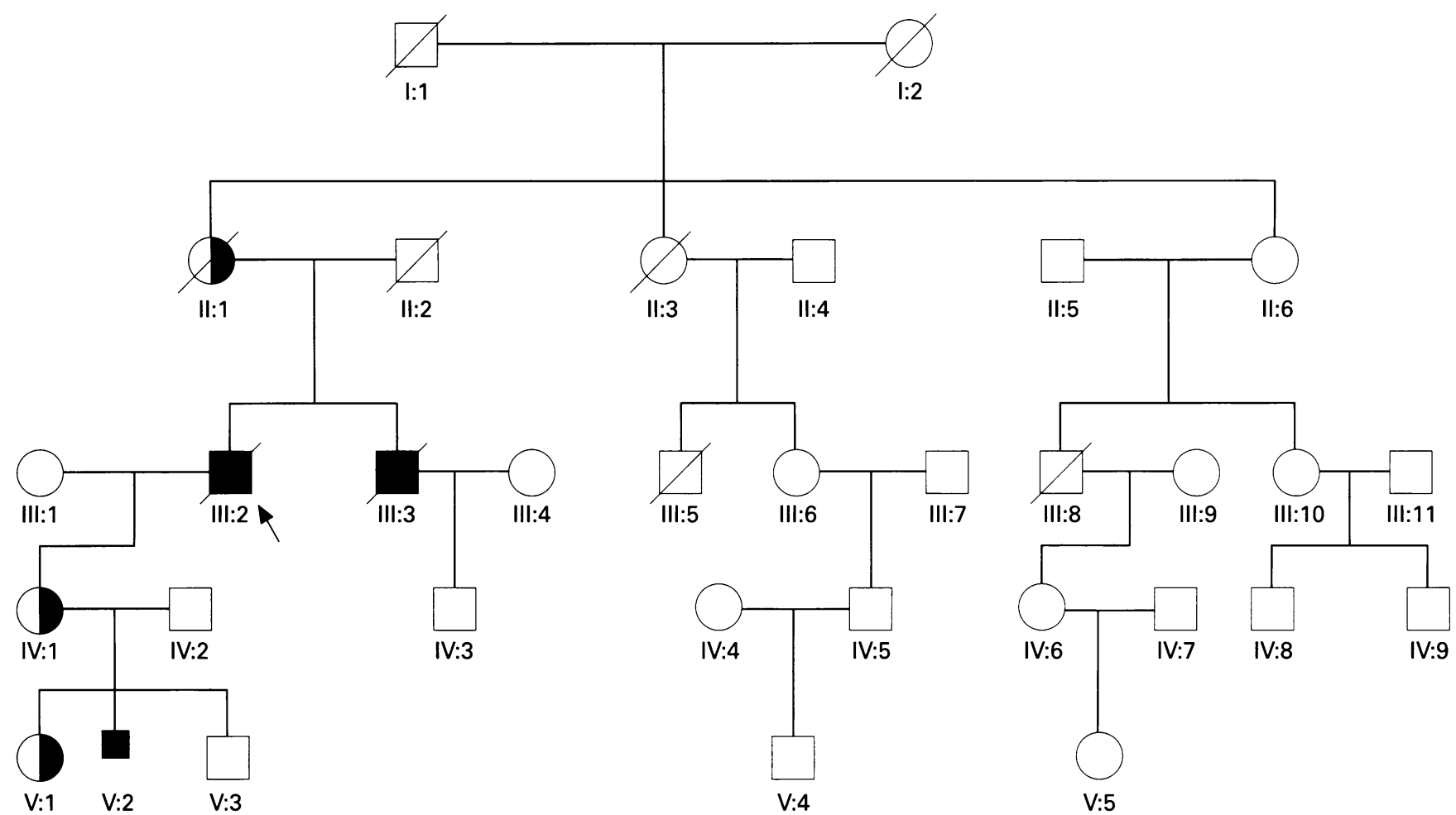

Figure 1 The Danish pedigree with the atypical form of Fabry disease.

room temperature, centrifuged and the supernatant removed. This step was repeated once and the residual xylene was removed by washing twice in $1 \mathrm{ml}$ absolute ethanol. After drying, the pellet was resuspended in $50 \mathrm{mM}$ Tris- $\mathrm{HCl}, \mathrm{pH} 8.3,1 \mathrm{mM}$ EDTA, $0.5 \%$ Tween 20 , and proteinase $\mathrm{K}(200 \mu \mathrm{g} / \mathrm{ml})$. The samples were incubated overnight at $55^{\circ} \mathrm{C}$. After inactivation of the proteinase for seven to eight minutes at $95^{\circ} \mathrm{C}$, the samples were centrifuged briefly and the supernatant was used for PCR. The supernatants were diluted to reduce the effect of inhibitory factors on Taq polymerase activity. ${ }^{11}$ Primers and PCR conditions for amplification of exon 6 were as described by Madsen et al. ${ }^{8}$ No amplicons were visible after agarose gel electrophoresis of PCR products from probands II:3 and III:8, but this was overcome by using a second round PCR, under the same conditions and using the same primers. For each PCR reaction a negative control lacking template DNA was also included. SSCP conditions were as described by Madsen et $a l,{ }^{8}$ except that a $5 \%$ MDE-gel (AT Biochem) without glycerol was used.

\section{Results and Discussion}

The diagnosis of the proband was confirmed by renal biopsy, which was performed because of unexplainable proteinuria and haematuria encountered in a routine examination. The cardiac symptoms developed several years later. The clinical manifestations in this patient were identical with those seen in the cardiac form of Fabry disease, as described by Ishii et $a l .{ }^{12}$ To date, seven unrelated patients with similar symptoms, from different parts of the world, have been described. ${ }^{1}$ All had late onset disease and presented mainly with cardiac symptoms and in some cases with proteinuria.

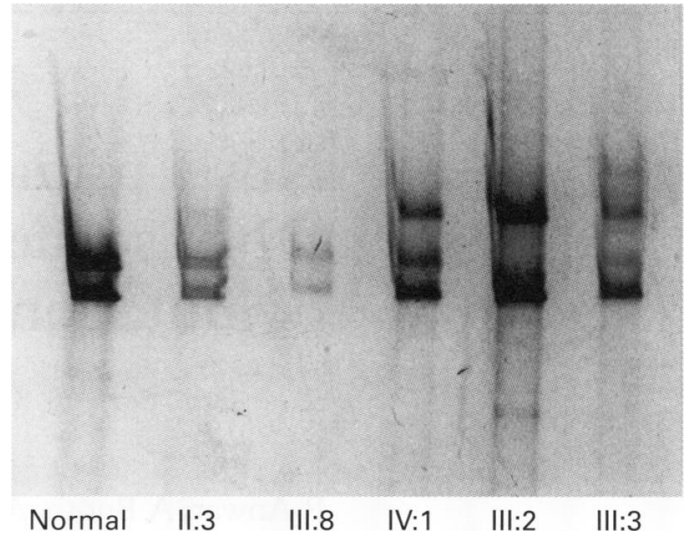

Figure 2 SSCP pattern, showing that III:3 had the same allele as his brother, III:2. The distant relatives, II:3 and III:8, have normal alleles.

PCR-SSCP analysis of DNA from formalin fixed, paraffin wax embedded tissue of the proband's brother, III:3, revealed a pattern identical with that of the proband (fig 2). The brother developed cardiac symptoms at the age of 36 years. He had no signs of classic Fabry disease, but because he had an identical mutation in the $\alpha$-gal A gene, we surmise that he also had the variant form of Fabry disease.

The detection of the mutation in the proband's brother ruled out the possibility of a de novo mutation in the proband and suggested that their mother was an obligate heterozygote. This, however, could not be confirmed by DNA analysis because no necropsy material from the mother was available.

The mother, II: 1 , had two sisters who are possible heterozygotes and, if so, may have passed the mutation to their progeny. A son, III:8, of one of the sisters died of cardiac disease at the age of 57 years. Paraffin wax embedded tissue was available from him and from the third sister, II:3. A normal exon 6 
SSCP pattern was found in both subjects, and therefore they did not have the mutation present in their relatives (fig 2). However, there is still a possibility that II:6, and therefore III: 10, are carriers of Fabry disease.

As patients with variant (cardiac) Fabry disease present mainly with cardiac symptoms resulting from cardiomyopathy, and because these patients have none or a mild form of the renal symptoms characteristic of the classic form of the disease, the correct diagnosis may be missed. The variant form is rare but may account for a few of the numerous cases of cardiac disease in men and should be considered when several cases of cardiac disease occur within a single family.

We thank Elsebeth Lund Christensen and Minna Becher for excellent technical assistance. This study was financially supported by the Danish Medical Research Council, Købmand i Odense Johann og Hanne Weimann f. Seedorffs legat, Signe and Peter Gregersens Mindefond and Novo's Fond.

1 Desnick RJ, Ioannou AI, Eng CM. $\alpha$-Galactosidase A deficiency: Fabry disease. In: Schriver CR, Beaudet AL, Sly
WS, Valle D, eds. The metabolic and molecular basis of inherWS, Valle D, eds. The metabolic and molecular basis of inher-
ited disease. 7th edn. New York: McGraw-Hill, 1995:

2 Komreich R, Desnick RJ, Bishop DF. Nucleotide sequence of the human $\alpha$-galactosidase A gene. Nucleic Acids Res
1989;17:3301-2.

3 Eng CM, Desnick RJ. Molecular basis of Fabry disease: Mutations and polymorphisms in the human $\alpha$-galactosidase A gene. Hum Mutat 1994;3:103-11.

4 Ploos van Amstel JK, Jansen RPM, de Jong JGN, Hamel BCJ, Wevers RA. Six novel mutations in the $\alpha$-galact, Wevers RA. Six novel mutations in the $\alpha$-galGenet 1994;3:503-5.

5 Davies J, Christomanou H, Winchester B, Malcolm S. Detection of 8 new mutations in the $\alpha$-galactosidase A gene in Fabry disease. Hum Mol Genet 1994;3:667-9.

6 Meaney C, Blanch LC, Morris P. A nonsense mutation $(\mathrm{R} 220 \mathrm{X})$ in the $\alpha$-galactosidase A gene detected in a female carrier of Fabry disease. Hum Mol Genet 1994;3:1019-20.

7 Eng CM, Niehaus DJ, Enriquez AL, Burgert TS, Ludman MD, Desnick RJ. Fabry disease: twenty-three mutations including sense and antisense $C P G$ alterations and identifiincluding sentifcation of a deletional hot-spot in the $\alpha$-galactosidase

8 Madsen KM, Hasholt L Sarensen SA, Fermér ML, Dahl $\mathrm{N}$. Two novel mutations (L32P) and (G85N) among five different missense mutations in six Danish families with Fabry's disease. Hum Mutat 1995;5:277-8.

9 Hasholt L, Sørensen SA, Wandall A. Clinical and biochemical findings in an atypic Fabry's disease hemizygote [abstract]. Vth International Congress of Inborn Errors of Metabolism. 1990.

10 Desnick RJ, Allen KY, Desnick SJ, Raman MK, Bemlohr RW, Krivit W. Fabry's disease: enzymatic diagnosis of hemizygotes and heterozygotes. 7 Lab Clin Med 1973;81: 157-71.

11 Kösel S, Graeber MB. Use of neuropathological tissue for molecular genetic studies: parameters affecting DNA extraction and polymerase chain reaction. Acta Neuropathol extraction and poly

12 Ishii S, Sakuraba H, Suzuki Y. Point mutation in the upstream region of the $\alpha$-galactosidase A gene exon 6 in an atypica variant of Fabry disease. Hum Genet 1992;89:29-32.

\title{
Novel primer specific false terminations during DNA sequencing reactions: danger of inaccuracy of mutation analysis in molecular diagnostics
}

\author{
R Anwar, A Booth, A J Churchill, A F Markham
}

Molecular Medicine Unit, University of Leeds, Department of Medicine, Clinical Sciences Building, St James's University Hospital,

Leeds LS9 7TF

Correspondence to: Dr R Anwar.

email:

msjra@stjames.leeds.ac.uk

Accepted for publication 18 July 1996

\begin{abstract}
The determination of nucleotide sequence is fundamental to the identification and molecular analysis of genes. Direct sequencing of PCR products is now becoming a commonplace procedure for haplotype analysis, and for defining mutations and polymorphism within genes, particularly for diagnostic purposes. A previously unrecognised phenomenon, primer related variability, observed in sequence data generated using Taq cycle sequencing and $\mathbf{T} 7$ Sequenase sequencing, is reported. This suggests that caution is necessary when interpreting DNA sequence data. This is particularly important in situations where treatment may be dependent on the accuracy of the molecular diagnosis.
\end{abstract}

(F Clin Pathol: Mol Pathol 1996;49:M312-M314)

Keywords: novel primer specific terminations, DNA sequencing, molecular diagnostics.
In the field of human genetics, every disorder studied at the molecular level requires nucleotide sequence determination. The information obtained from mutation analysis is often essential for understanding the structure and function of the proteins encoded by the genes under study. Identification of mutation(s) in a particular gene, which consistently segregates with the disease phenotype in pedigrees, provides proof that a given candidate gene is really the 'disease' gene in a specific inherited condition. The accuracy of mutation analysis is especially important for prenatal diagnosis where the continuation of a pregnancy may be dependent on the results of the molecular assay.

The dideoxy chain terminator DNA sequencing method is the most popular procedure because of its practical simplicity. It was originally described by Sanger et al ${ }^{1}$ and many modifications to the original protocol have been introduced over the years. The two most common methods of DNA sequencing at 